Волокитина И. Е. Волокитин А. В.

\title{
ИЗМЕНЕНИЕ МЕХАНИЧЕСКИХ СВОЙСТВ ПРОВОЛОКИ ПРИ КРИОГЕННОМ ОХЛАЖДЕНИИ В ПРОЦЕССЕ ВОЛОЧЕНИЯ
}

Для осуществления планов, стоящих перед экономикой Республики Казахстан необходимо обеспечение основных отраслей промышленности качественной металлопродукцией, обладающей уникальными физическими, механическими и другими эксплуатационными свойствами. Часто решение этих задач связано с высокими энергозатратами. В условиях бережливого использования энергетических и сырьевых ресурсов, проблема энерго- и ресурсосберегающих способов получения материалов со свойствами, сочетающими одновременно высокую прочность и пластичность, в условиях использования относительно простых и недорогих устройств, позволяющих затрачивать минимально возможное количество времени при обработке изделий имеет большое практическое значение [1].

На данный момент высокую актуальность приобрели работы, связанные с получением металлоизделий в одной непрерывной линии путем комбинирования и совмещения операций. Такой подход ведет к повышению конкурентоспособности за счет снижения количества промежуточных операций.

Одним из важнейших видов металлоизделий является стальная проволока, широко используемая как конструктивный элемент при производстве канатов, металлокорда и биметаллической сталемедной продукции (проволока и неизолированные провода). Данные металлоизделия определяют безопасность и надежность функционирования железных дорог, агрегатов для подъема (перемещения) людей или грузов, несущих строительных конструкций самых различных объектов и сооружений, телефонных проводов, специальных микрокабелей, авиа- и сейсмографических кабелей, объектов оборонной промышленности, авиации и др. В настоящее время предъявляются все более жесткие требования к уровню регламентируемых свойств указанных металлических изделий. Традиционные технологии повышения уровня механических свойств стальной проволоки не имеют существенного резерва по таким технико-экономическим показателям, как рентабельность, энергоемкость, ограниченная возможность оперативного изменения, как всего технологического процесса, так и отдельных его параметров. Поэтому разработка технологических мероприятий и технических средств, обеспечивающих комплексное повышение механических свойств стальной проволоки с использованием инновационных способов деформационной обработки, является важной научно-технической проблемой [2].

Измельчение размера зерен в конструкционных материалах может существенно улучшить их прочностные характеристики в условиях холодной деформации и пластические в условиях горячей. Как следствие, имеет место устойчивый практический интерес к разработке технологий, позволяющих радикально уменьшить размер зерен. В настоящее время перед материаловедами стоит задача формирования субмикро- и нанокристаллических структур, причем в объёмах, пригодных для промышленного использования. Одним из возможных способов решения этой задачи может служить деформация при температуре жидкого азота (так называемая криогенная деформация). Предполагается, что крайне низкие температуры деформации значительно затруднят процессы возврата и, тем самым, существенно ускорят измельчение микроструктуры [3].

В последние годы возрос интерес к использованию возможностей криогенного охлаждения с использованием жидкого азота во время деформации методами обработки давлением [3-5]. В области машиностроения низкотемпературная или холодная обработка впервые была предложена в 1937 году советским ученым А. С. Гуляевым [6] и позже стал использоваться за рубежом. Для многих марок углеродистых и легированных сталей полный конец мартенситного превращения происходит при минусовых температурах, поэтому при охлаждении до комнатной температуры в структуре остается определенное количество аустенита. 
Многоразовыми высокотемпературными закалками дальнейшее изменение структуры осуществить нельзя. Это означает, что максимально возможное значение твердости для данной стали не достигается. Кроме того, остаточный аустенит с течением времени может постепенно превращаться в бейнит, поэтому желательно наиболее полно перевести аустенит в мартенсит. Это достигается путем охлаждения до конечной температуры мартенситного превращения $\mathrm{M}_{\mathrm{K}}$, которая может находиться в диапазоне от плюс до $-140^{\circ} \mathrm{C}$ для промышленных марок стали. Кроме того, криогенная обработка не сопровождается динамическим возвратом или перекристаллизацией, что позволяет более эффективно измельчать зернистую структуру. Еще одним преимуществом такой деформации является значительное увеличение прочности при меньших деформационных силах по сравнению с традиционными методами обработки металла давлением [7].

Поэтому предлагается применение интенсивного охлаждения при выходе проволоки из волоки с помощью жидкого азота, что даст более выгодный компромисс между прочностью и пластичностью материала. Это может быть достигнуто благодаря повышенной подвижности дислокаций и, вместе с тем, их повышенной плотности.

Целью настоящей работы является изучение закономерностей изменения механических свойств низкоуглеродистой стали в зависимости от температуры ее деформирования волочением при комнатной и криогенной температурах. Выбор стали в качестве материала исследования обусловлен его большой практической значимостью, а также необходимостью одновременного повышения его прочностных и пластических свойств.

Процесс волочения проволоки с криогенным охлаждением (рис. 1). Технология представляет собой совмещенный процесс обработки металла давление с последующей термической обработкой в одной линии агрегата. Процесс задачи проволоки ни чем, ни отличается от существующей технологии волочения и задачи проволоки в стан. Заостренный конец проволоки задается в волоку, установленную в волокодержателе стана, затем пропускается через пустой резервуар-камеру для криогенного охлаждения. Далее конец проволоки закрепляется на барабане волочильного стана, происходит наматывание несколько витков проволоки. Далее стан выходит на рабочую скорость волочения. В это же время происходит заполнение камеры криогенного охлаждения жидким азотом. Камера снабжена рециркулярной системой подачи азота [2].

Технологический процесс представляет собой протягивание проволоки через фильеру с уменьшением поперечного сечения и последующего интенсивного охлаждения. В очаге деформации происходит интенсивный разогрев проволоки, температура доходит до $+120 \div 150{ }^{\circ} \mathrm{C}$, далее проволока попадает в камеру криогенного охлаждения где происходит интенсивное охлаждение порядка $-200 \div-196{ }^{\circ} \mathrm{C}$.

Экспериментально показано, что применение криогенной деформационной обработки волочением позволяет обеспечить повышение комплекса механических свойств по сравнению с традиционным волочением. В частности, при обработке проволоки из низкоуглеродистой стали временное сопротивление разрыву повышается на $10 \%$, условный предел текучести - на 11,5\%, относительное сужение после разрыва понижается на 6 \%.

Однородность формируемой структуры по сечению проволоки после разработанного метода подтверждена результатами измерения микротвердости. В проволоке из стали марки Ст3 диаметром 5,0 мм криогенное охлаждение вызывает увеличение микротвердости в центральной области с 1320 МПа до 1745 МПа, причем на поверхности изменение микротвердости составляет от 1347 МПа до 1842 МПа.

Ударная вязкость стальной проволоки после однократного волочения аналогично исходному материалу, в интервале температур $-120 \ldots-196^{\circ} \mathrm{C}$ наблюдается снижение вязкости. Хотя значение $\mathrm{KCU}$, равное 24 Дж/см² при $-196^{\circ} \mathrm{C}$, является достаточно высоким.

Чтобы определить однородность механических свойств, мы использовали коэффициент вариации случайной величины (мера относительного разброса случайной величины, которая показывает, сколько из среднего значения этого значения составляет ее средний разброс), рассчитанный как отношение среднего арифметического образца к стандартному отклонению. Оценка однородности механических свойств по схеме показала, что разброс механических свойств по длине получаемой проволоки не превышает значений, разрешенных международным стандартом. 


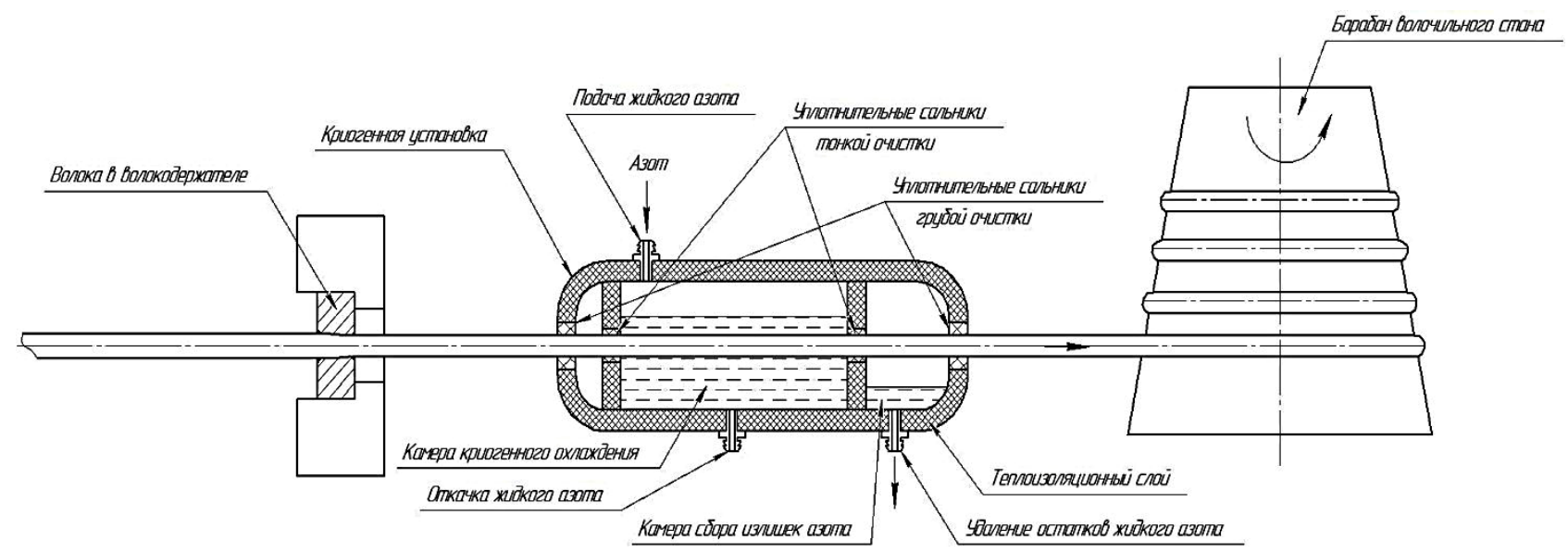

Рис. 1. Схема криогенного охлаждения проволоки

Увеличение прочностных характеристик после криогенного волочения по сравнению с волочением при комнатной температуре в целом может быть связано с ростом степени дефектности структуры, уровнем ее фрагментации и изменением состояния границ фрагментов.

При анализе фрактографии разрушения после волочения стали при комнатной температуре трещина вязкая, она проходит через зернистое тело, что характерно для волокнистого разрушения. Поверхность трещины в зоне зарождения трещины представлена глубокими ямами отрыва, которые вытянуты в направлении распространения трещины. Зона распространения трещины представлена равноосными ямами разных размеров. Ямы Долома выглядят как впадины с более или менее тонкими перемычками. Перелом после испытания при криогенной температуре имеет вид сухого фиброзного перелома, он представляет собой гомогенную поверхность вязкого внутризеренного перелома с менее выраженными признаками пластической деформации по всей поверхности перелома, чем у фиброзного перелома. Относительно тонкие перемычки между ремнями в трещинах при комнатной и криогенной температурах теста свидетельствуют об энергоемком процессе разрушения.

Для сравнения уровня механических свойств малоуглеродистой стальной проволоки с комплексом свойств, сформированным в результате разработанной совмещенной деформационной обработки «прессование-волочение». Данную совмещенную технологию выбрали из-за того, что она является непрерывным методом деформационного наноструктурирования углеродистой стальной проволоки, данный метод легко встраивается в технологию производства проволоки без существенного ее изменения. Скорости обработки проволоки как при разработанном в данной статье методе, так и при «прессовании-волочении» приблизительно одинаковы. Кроме того, накоплен богатый экспериментальный материал по уровню механических свойств углеродистой стальной проволоки после совмещенной технологии «прессование-волочение». В качестве данных для сравнения были использованы значения механических свойств малоуглеродистой стали Ст.3 [8-10].

Процесс «прессование-волочение» позволяет получить относительно невысокую интенсивность изменения свойств малоуглеродистой проволоки за 1 проход по сравнению с применением криогенного охлаждения в процессе деформирования. При этом предлагаемый метод волочения с криогенным охлаждением позволяет достичь увеличения временного сопротивления разрыву низкоуглеродистой проволоки из стали марки Ст3 за 1 проход по сравнению с совмещенной технологией «прессование-волочение» приблизительно на 70-100 МПа относительно исходного состояния.

\section{ВЫВОДЫ}

В статье проведено исследование изменения механических свойств проволоки при криогенном охлаждении в процессе волочения, в результате которого можно сделать следующие выводы: 
- при криогенной обработке проволоки из низкоуглеродистой стали временное сопротивление разрыву повышается на $10 \%$, условный предел текучести - на 11,5\%, относительное сужение после разрыва понижается на $6 \%$;

- криогенные условия деформации волочением являются дополнительным фактором реализации структурного ресурса для оптимизации физико-механических свойств стали.

\section{СПИСОК ИСПОЛЬЗОВАННОЙ ЛИТЕРАТУРЫ}

1. Лежнев С. Н., Волокитина И. Е., Волокитин А. В. Влияние процесса прессование-волочение на изменение структуры и механических свойств стали. Сталь. 2017. 3. С. 44-48.

2.Турдалиев А. Т., Абуова А. Х., Волокитина И. Е., Волокитин А. В. Механические свойства мало-углеродистой стали после волочения в криогенных условиях. Промыциленный транспорт Казахстана. 2019. 3. С. 159-163.

3. Konkova T.N., Mironov S.Yu., Korznikov A.V. Intense cryogenic deformation of copper. FMM. 2010. 109, pp. 184-187.

4. Nayan N., Narayana S.V.S., Abhay K.Jha, Bhanu Pant, Sharma S.C., et al. Mechanical properties of aluminium-copper-lithium alloy AA2195 at cryogenic temperatures. Mater. Des. 2014. 58, pp. 445-450.

5. Li Y.S., Tao N.R., Lu K. Microstructural evolution and nanostructure formation in copper during dynamic plastic deformation at cryogenic temperatures. Acta Mater. 2008. 56, pp. 230-241.

6. Гуляев А.П. Термическая обработка стали. Москва: ГНТИ. 1953. 384 с.

7. Nadig D.S., Ramakrishnan V., Sampathkumaran P., Prashanth C.S. Effect of cryogenic treatment on thermal conductivity properties of copper. Advances in Cryogenic Engineering AIP Conf. Proc. 2012. 1435, pp. 133-139.

8. Лежнев С.Н., Волокитина И.Е., Волокитин А.В. Изменение структуры медной проволоки при деформации методом «прессование-волочение». Обработка материалов давлением. Краматорск: ДГМА. 2017. 2 (45). С. 123-128.

9. Naizabekov A., Volokitina I., Volokitin A., Panin E.. Structure and mechanical properties of steel in the process "pressing-drawing. Journal of Materials Engineering and Performance.2019. 28. 1, pp. 1762-1771.

10. Lezhnev S.N., Volokitina I.E., Volokitin A.V. Evolution of Microstructure and Mechanical Properties of Steel during Pressing-Drawing. Physics of Metals and Metallography. 2017. 118. 11, pp. 1167-1170.

\section{REFERENCES}

1. Lezhnev S.N., Volokitina I.E., Volokitin A.V. The influence of the pressing-drawing process on the change in the structure and mechanical properties of steel. Steel. 2017. 3, pp. 44-48. (in Russian).

2. Turdaliev A.T., Abuova A.Kh., Volokitina I.E., Volokitin A.V. Mechanical properties of low carbon steel after drawing under cryogenic conditions. Industrial transport of Kazakhstan, 2019, 3, pp. 159163. (in Russian).

3. Konkova T.N., Mironov S.Yu., Korznikov A.V. Intense cryogenic deformation of copper. FMM. 2010. 109, pp. $184-187$.

4. Nayan N., Narayana S.V.S., Abhay K. Jha, Bhanu Pant, Sharma S.C., et al. Mechanical properties of aluminum - copper - lithium alloy AA2195 at cryogenic temperatures. Mater. Des. 2014. 58, pp. 445-450.

5. Li Y.S., Tao N.R., Lu K. Microstructural evolution and nanostructure formation in copper during dynamic plastic deformation at cryogenic temperatures. Acta Mater. 2008. 56, pp. 230-241.

6. Gulyaev A.P. Heat treatment of steel. Moscow: GNTI, 1953. 384 p. (in Russian).

7. Nadig D.S., Ramakrishnan V., Sampathkumaran P., Prashanth C.S. Effect of cryogenic treatment on thermal conductivity properties of copper. Advances in Cryogenic Engineering AIP Conf. Proc. 2012.1435, pp. 133-139.

8. Lezhnev S.N., Volokitina I.E., Volokitin A.V. Change in the structure of a copper wire upon deformation by the “pressing-drawing" method. Materials Working by Pressure. Kramatorsk: DSEA. 2017. 2 (45), pp. 123-128. (in Russian).

9. Naizabekov A., Volokitina I., Volokitin A., Panin E.. Structure and mechanical properties of steel in the process "pressing-drawing. Journal of Materials Engineering and Performance, 2019, 28, 1, pp. 1762-1771.

10. Lezhnev S.N., Volokitina I.E., Volokitin A.V. Evolution of microstructure and mechanical properties of steel during pressing - drawing. Physics of Metals and Metallography. 2017. 118. 11, pp. 1167-1170.

Волокитина И. Е. - - PhD, доцент КГИУ;

E-mail: irinka.vav@mail.ru; https://orcid.org/0000-0002-2190-5672

Волокитин А. В. - PhD, ст. преп. КГИУ.

E-mail: dyusha.vav@mail.ru; https://orcid.org/0000-0002-0886-3578

КГИУ - Карагандинский государственный индустриальный университет, г. Темиртау, Казахстан. 